Agrotrópica 32(3): 177 - 188. 2020.

Centro de Pesquisas do Cacau, Ilhéus, Bahia, Brasil

\title{
SISTEMA AGROFLORESTAL COM CACAUEIROS E ESSÊNCIAS FLORESTAIS: DESEMPENHO AGRONÔMICO, CLONAGEM E ANÁLISE ECONÔMICA
}

\author{
Caio Márcio Vasconcellos Cordeiro de Almeida ${ }^{1}$, Fernando Luíz de Oliveira Corrêa ${ }^{2}$, Antônio \\ de Almeida Lima ${ }^{2}$, Amarildo Pinheiro Virgulino ${ }^{1}$, Ivan Pires Xavier ${ }^{3}$
}

\begin{abstract}
${ }^{1}$ CEPLAC/CEPEX-RO, Avenida Governador Jorge Teixeira, no 86, Bairro Nova Porto Velho, 76.820-096, Porto Velho, Rondônia, Brasil. caio.almeida@agricultura.gov.br. ${ }^{2}$ CEPLAC/CEPEX-RO/ESEOP, BR 364, km 325, 76.920 - 000, Ouro Preto do Oeste, Rondônia, Brasil. ${ }^{3}$ CEPLAC/CEPEX-RO/ELOUP, Rua JK, 347, Centro, 76.920 - 000, Ouro Preto do Oeste, Rondônia, Brasil.
\end{abstract}

Trata-se de estudo de caso para avaliar sistema agroflorestal (SAF) com variedades híbridas de cacaueiros e essências florestais convertido em SAF com variedades clonais, abordando os aspectos agronômicos da implantação e do manejo, a conversão da plantação híbrida em plantação clonal, além da rentabilidade do cultivo. O estudo foi realizado no Sítio Rio Branco, em Ouro Preto do Oeste, Rondônia, em 2,24 hectares de cacaueiros, implantados em 2003. Com os baixos níveis de produtividade obtidos até 2011 , inferiores a $400,0 \mathrm{~kg} \mathrm{ha}^{-1}$ de amêndoas secas de cacau, foi revelada a necessidade de se fazer uso de fertilização química, por se tratar de solos com baixo teor de fósforo e mediano de potássio. As fertilizações realizadas nos anos seguintes elevaram a produtividade das variedades híbridas para patamar superior a 1.300,0 $\mathrm{kg} \mathrm{ha}^{-1}$, em $2014 \mathrm{e} 2015$. Em paralelo, entre $2012 \mathrm{e} 2014$, e em 2018, o produtor substituiu, gradativamente, as variedades híbridas pelos clones CCN 51, PH 16, SJ 02, PS 1319, CCN 10 e BN 34, utilizando a enxertia por garfagem de topo em fenda cheia. Em 2018, acrescentou às tecnologias em uso, a irrigação por micro aspersão, quando obteve os maiores níveis de produtividade, atingindo o patamar de 2.057,1 kg ha, em 2019. A análise econômica do período de 2005 a 2019 revelou Taxa Interna de Retorno - TIR de 26\%, o que demonstra a viabilidade econômica do sistema de produção. A Renda Bruta Descontada - RDB e o Valor Presente Líquido - VPL tiveram melhor desempenho no ano de 2019, com valores líquidos de: $\mathrm{R} \$ 47.594,83$ e $\mathrm{R} \$ 15.732,91$, respectivamente, coincidente com a maior produtividade obtida. A adoção correta das práticas de manejo agronômico resultou em maior performance produtiva tanto para as variedades híbridas como para as variedades clonais.

Palavras-chave: intercultivo, produtividade, variedades híbridas, variedades clonais, Theobroma cacao L.

Agroforestry system with cocoa trees and forest essences: agronomic performance, cloning and economic analysis. This is a case study to evaluate the agroforestry system (SAF) with hybrid varieties of cocoa trees and forest essences converted into SAF with clonal varieties, addressing the agronomic aspects of implantation and management, the conversion of the hybrid plantation to clonal plantation, in addition to cultivation profitability. The study was carried out at Sítio Rio Branco, in Ouro Preto do Oeste, Rondônia, on 2.24 hectares of cocoa trees, implanted in 2003. With the low levels of productivity obtained until 2011, below $400.0 \mathrm{~kg} \mathrm{ha}^{-1}$ of almonds cocoa droughts, the need to use chemical fertilization was revealed, as they are soils with low phosphorus and medium potassium. The fertilizations carried out in the following years raised the productivity of hybrid varieties to a level higher than $1,300.0 \mathrm{~kg} \mathrm{ha}^{-1}$, in 2014 and 2015. In parallel, between 2012 and 2014, and in 2018, the producer gradually replaced hybrid varieties by clones CCN 51, PH 16 , SJ 02, PS 1319, CCN 10 and BN 34, using grafting top forks in full slits. In 2018, it added micro sprinkler irrigation to the technologies in use, when it achieved the highest levels of productivity, reaching the level of $2,057.1 \mathrm{~kg}$ ha in 2019. The economic analysis for the period from 2005 to 2019 revealed an Internal Rate of Return - 26\% IRR, which demonstrates the economic viability of the production system. Gross Discounted Income - RDB and Net Present Value - NPV performed better in 2019, with net values of: R \$47,594.83 and R \$15,732.91, respectively, coinciding with the higher productivity obtained. The correct adoption of agronomic management practices resulted in greater productive performance for both hybrid and clonal varieties.

Key words: intercultural, productivity, hybrid varieties, clonal varieties, Theobroma cacao L. 


\section{Introdução}

Sustentabilidade na agricultura é um dos temas atuais de discussão no meio técnico-científico para entender as causas que dificultam a permanência do homem no meio rural, levando-o a migrar para os centros urbanos do país em busca de melhores condições de vida. Conceitualmente, refere-se às ações e atividades humanas que visam suprir as necessidades atuais dos seres humanos, sem comprometer o futuro das próximas gerações (Sustentabilidade, 2020), ou atender a demandas crescentes da sociedade utilizando os recursos naturais finitos de forma inteligente (Lopes e Contini, 2012), ou ainda, à capacidade de os agricultores familiares conservarem ou aumentarem sua qualidade de vida mantendo e garantindo recursos para as próximas gerações (Gomes, 2005). Nas muitas vertentes de abordagem, há destaque para os aspectos técnicos, com ênfase às tecnologias em uso, as questões ambientais e sociais envolvidas, o acesso ao crédito agrícola, o associativismo e o cooperativismo, além da rentabilidade econômicofinanceira do empreendimento rural.

A cacauicultura rondoniense, desde sua implantação em bases tecnificadas na década de 1970, defrontouse com limitações de diversas naturezas para se estabelecer de forma sustentável. Fatores impostos pelos baixos preços do produto no mercado internacional, a carência de mão de obra no meio rural onerando os custos de produção, a virulência da vassoura-de-bruxa (Moniliophthora perniciosa), principal enfermidade do cacaueiro (Theobroma cacao L.) na região, entre outros fatores (Almeida, Matos e Destro, 2011), constituíram óbices para o fortalecimento desse polo cacaueiro, inclusive para a implantação e permanência de indústrias de processamento de amêndoas secas.

Atualmente, o polo rondoniense é constituído de aproximadamente 9,4 mil hectares de cacaueiros que produzem em torno de 5,3 mil toneladas de amêndoas secas, com rendimento médio de $561 \mathrm{~kg} \mathrm{ha}^{-1}$ de amêndoas secas, representando o quarto estado brasileiro produtor desta commodity (IBGE, 2020). Nos últimos anos, a comunidade rural regional tem despertado o interesse pela implantação de variedades clonais, em virtude de informações do elevado desempenho agronômico desses materiais genéticos nos estados da Bahia e Espírito Santo (CEPLAC, 2002; Lopes et al., 2004; Pires, Rosa e Macêdo, 2012; CEPLAC, 2014; Lopes et al., 2018; Monteiro et al., s.d.; Pires et al., s.d.).

A utilização de variedades híbridas ou de variedades clonais de cacau em sistema agroflorestal aliada às práticas de manejo agronômico recomendadas para o cultivo do cacaueiro na Amazônia brasileira podem proporcionar aumento na produtividade e, consequentemente, aumento na renda do produtor. Este estudo de caso objetiva avaliar um sistema agroflorestal (SAF) com variedades híbridas de cacaueiros e essências florestais convertido em SAF com variedades clonais, abordando os aspectos agronômicos da implantação e manejo do plantio, da conversão da plantação híbrida em plantação clonal, além da rentabilidade do cultivo agrícola.

\section{Material e Métodos}

Este estudo foi realizado em área de intercultivo de cacaueiros e essências florestais no Sítio Rio Branco, localizado no lote 15 , gleba 20 D, linha 20/81, do antigo Projeto Integrado de Colonização Ouro Preto, atual município de Ouro Preto do Oeste (10 37'30” S; $62^{\circ}$ 07’30"W), Rondônia. Na década de 1970, a vegetação natural da floresta equatorial primária dessa área foi derrubada para formação de pastagem, a qual foi explorada até 1983, quando já apresentava sinais de degradação. Nessa ocasião, fez-se uso de duas aplicações de herbicida sistêmico para eliminar as gramíneas componentes da pastagem. No período de 1984 a 1999 a exploração da pastagem foi substituída pelo plantio e exploração de cacaueiros de variedades híbridas, em face de o produtor rural já ter tradição com esse cultivo e como uma opção econômica. No ano de 2000 , em razão da baixa produtividade do cacaual, malformação da maioria das plantas em virtude de poda malfeita e elevada ocorrência da broca-dos-frutos (Conotrachelus humeropictus), o plantio de cacaueiros foi substituído por cafeeiros (Coffea canephora), variedade Conilon, que foram explorados apenas até 2002, quando o produtor retornou ao cultivo de cacaueiros no ano seguinte, objeto deste estudo de caso.

O produtor rural é oriundo do município de Linhares, no estado do Espírito Santo, onde exercia atividades agrícolas com o cultivo de cacaueiros e espécies 
alimentares, como: feijão, milho e mandioca, em propriedade da família. A migração para Rondônia decorreu das facilidades de aquisição de terras férteis, estimulado também pela propaganda oficial para ocupação dos chamados vazios demográficos da Amazônia e por parentes que aqui já se encontravam. Apresenta como escolaridade o $1^{\circ}$ grau e residência na propriedade rural desde 1982, ano da sua aquisição.

A região em foco caracteriza-se por apresentar clima tropical quente e úmido, do tipo Aw - Clima Tropical Chuvoso, de acordo com a classificação de Köppen, com média anual da temperatura do ar variando de $24^{\circ} \mathrm{C}$ a $26^{\circ} \mathrm{C}$ e um período seco bem definido (junho a agosto), quando ocorre um moderado déficit hídrico com índices pluviométricos inferiores a $50 \mathrm{~mm}$ mês ${ }^{-1}$. A precipitação pluviométrica anual varia de 1400 $\mathrm{mm}$ a $2600 \mathrm{~mm}$. A área estudada apresenta topografia plana, e solo classificado como Cambissolo Háplico Eutrófico, conforme Sistema Brasileiro de Classificação de Solos (Santos et al., 2006).

A metodologia adotada no estudo consistiu de entrevista e aplicação de questionário com o proprietário e seu filho, complementada com dados disponibilizados pelo escritório de extensão rural de Ouro Preto do Oeste e pelo técnico da Comissão Executiva do Plano da Lavoura Cacaueira - CEPLAC que presta assistência técnica à propriedade. Tais informações serviram para caracterizar os diferentes aspectos relacionados à implantação, manejo, clonagem dos cacaueiros e sócio economia do sistema agroflorestal.

$\mathrm{Na}$ análise econômica, os indicadores utilizados foram: o Valor Presente Líquido (VPL), Taxa Interna de Retorno (TIR), Receita Bruta Descontada (RBD), Despesa Bruta Descontada (DBD), além dos indicadores de desempenho: Jornada de Trabalho, Produção, Produtividade e Produtividade Esperada. O VPL, também conhecido como Valor Atual Líquido (VAL) ou método do valor atual, é a fórmula econômicofinanceira capaz de determinar o valor presente de pagamentos futuros descontados a uma taxa de juros apropriada, menos o custo do investimento inicial. Além disso, leva em consideração o custo de capital da propriedade rural, na forma da Taxa Mínima de Atratividade (TMA) ou taxa de desconto, para a qual considerou-se de 2,5\% ao ano (a.a.), aplicada atualmente nas operações do Programa Nacional da
Agricultura Familiar (PRONAF Floresta e/ou mais Alimento).

Outro indicador utilizado para melhorar o entendimento do retorno do investimento é a TIR. Ela serve para transformar o produto do cálculo de VPL em valores reais. É uma medida relativa, expressa em percentual, que demonstra o quanto rende um projeto de investimento, considerando a mesma periodicidade de seus fluxos de caixa.

Para o cálculo desses indicadores utilizaram-se as seguintes formulas (Silva, Jacovine e Valverde, 2005):

$$
V P L=\sum_{n=1}^{n=N} \frac{F C_{t}}{(1+i)^{n}}
$$

Em que:

$\mathrm{FCt}=$ Fluxo de Caixa no período de tempo

$\mathrm{i}=$ Taxa de Juros ou Taxa Mínima de Atratividade (TMa)

$n=$ Período final a ser analisado

$$
T I R=\sum_{T=0}^{n} \frac{F n}{(1+i)^{n}}=0
$$

Em que:

Fn = Fluxo de Caixa no Período de tempo.

$$
\begin{aligned}
& \mathrm{DBD}=\frac{D B}{(1+i)^{n}} \\
& \mathrm{RBD}=\frac{R B}{(1+i)^{n}}
\end{aligned}
$$

Em que:

$\mathrm{RBD}=$ Receita Bruta Descontada

DBD $=$ Despesa Bruta Descontada

$\mathrm{RB}=$ Receita Bruta

$\mathrm{DB}=$ Despesa Bruta

Os indicadores RBD e DBD são importantes para a gestão financeira de uma propriedade rural, pois informam sobre o valor necessário para o custeio das atividades previstas no sistema de produção adotado, bem como seu montante num dado horizonte de tempo. Ao se obter o valor total das receitas e das despesas do período em análise, submetido a uma TMA, abrangendo os gastos com jornada de trabalho, 
insumos, transporte, impostos e/ou outros, o valor resultante representa o lucro ou a renda líquida gerada pelo sistema de produção adotado.

Muito embora o rigor metodológico adotado nas coletas e análises dos dados desta pesquisa, mas, por se tratar de um estudo de caso de uma única unidade produtiva onde se procura descrever e explicar a conversão de um plantio de variedades híbridas em plantio de variedades clonais de cacau, os resultados apresentados a seguir devem ser vistos com a cautela decorrente ao processo amostral.

\section{Resultados e Discussão}

\section{Implantação, manejo das atividades agroflorestais e desempenho agronômico}

Em janeiro de 2003, o produtor rural implantou, com recursos próprios, 2,3 ha de cacaueiros em sistema agroflorestal no espaçamento de 3,0 m x 3,0 m, em covas de dimensões de $25 \mathrm{~cm} \times 25 \mathrm{~cm} \times 25 \mathrm{~cm}$, utilizando mudas de cacau com quatro meses de idade, formadas a partir de sementes de variedades híbridas produzidas na Estação Experimental Ouro Preto ESEOP, pertencente à CEPLAC. Em geral, tais variedades híbridas de cacaueiros produzidas e distribuídas em Rondônia são formadas por mescla homogênea de pelo menos oito a dez cruzamentos interclonais.

Anteriormente ao plantio de cacaueiros, em novembro e dezembro de 2002, implantou bananeiras (Musa sp.) no espaçamento de 3,0 $\mathrm{m}$ x 3,0 m, para formação do sombreamento provisório. Também, utilizou as entrelinhas do SAF, no primeiro ano, para cultivo de milho, destinado preferencialmente à subsistência da família. A produção da banana foi utilizada como fonte de alimento e renda até o $3^{\circ}$ ano do plantio.

O sombreamento definitivo foi formado a partir de componentes da regeneração natural da vegetação, de acordo com a preferência do produtor, e implantação de algumas espécies, conforme a seguir: bandarra (Schizolobium parahyba var. amazonicum), biribazeiro (Rollinia mucosa), branquilho (Sebastiana brasiliensis), cedro-rosa (Cedrella odorata), cerejeira (Amburana acreana), freijó (Cordia sp.), garrote (Bagassa guianensis), imbireira (Couratari stellata), ingazeira (Inga sp.), ipê (Tabebuia sp.), itaúba (Mezilaurus itauba), jenipapeiro (Genipa caruto), pitangueira (Eugenia uniflora), roxinho (Tradescantia pallida) e seringueira (Hevea brasiliensis). Por se tratar de processo de regeneração espontânea da vegetação natural e implantação aleatória de algumas espécies, o espaçamento é irregular entre esses componentes arbóreos.

As informações obtidas evidenciaram que foram utilizados, rotineiramente, os seguintes tratos culturais no manejo do SAF em análise: i) roçagem - duas por ano, utilizando biscol até 2009 , e roçadeira motorizada, de 2010 em diante; ii) desbrota dos cacaueiros - duas por ano; iii) poda fitossanitária - realizada de agosto a outubro para o controle cultural da vassoura-de-bruxa e iv) beneficiamento primário do cacau compreendendo colheita, amontoa e quebra dos frutos, fermentação e secagem das sementes realizadas em lona, por não possuir estrutura convencional de beneficiamento. Ocasionalmente, realizou o controle químico de insetos-praga, sobretudo do monalônio (Monalonion annulipes). A presença frequente da broca-dos-frutos ocasionando danos significativos à produção, e a inexistência de controle químico para essa praga levou o produtor a adotar a estratégia de controle cultural, por meio do ajuntamento dos frutos de cacau sobre lonas plásticas para realizar a quebra e a retirada das sementes, e assim, evitar que as larvas se dirijam para o solo, conforme recomendação de Trevisan et al. (2012). Em 2004, replantou aproximadamente 500 cacaueiros utilizando mudas de variedades híbridas.

Em junho de 2007, em razão da baixíssima produtividade dos cacaueiros, pesquisadores e extensionistas da CEPLAC realizaram supervisão técnica para estabelecer um diagnóstico para esse baixo desempenho agronômico. Na ocasião, observouse que os poucos frutos de cacau encontrados revelavam, pela sua diversidade fenotípica, a presença de mescla de diversos cruzamentos interclonais, um indicativo do plantio das variedades híbridas distribuídas em Rondônia e da adequada população de polinizadores na área, além de inexistência de quaisquer restrições decorrentes de fator genético, a exemplo de incompatibilidade sexual. Observou-se também boa drenagem da área de plantio e que a maioria dos 
cacaueiros e plantas sombreadoras apresentavam sinais de raquitismo (plantas pequenas e finas) e de desnutrição (folhas pequenas, cloróticas, outras estreitas, outras com necrose marginal), o que direcionava para deficiência nutricional (Figura 1). Ademais, muito embora a área em cultivo fosse explorada desde a década de 1970, ou seja, há mais de 30 anos, o produtor rural nunca havia realizado qualquer tipo de reposição nutricional ao solo, decorrente da crença equivocada de dispensa desta prática, por se tratar, a área de cultivo, de solos de média a alta fertilidade natural. Em julho de 2007, logo após essa visita técnica, os resultados das análises químicas do solo revelaram essa assertiva de deficiência nutricional nas plantas (Tabela 1).

Sabe-se que o cacaueiro é uma espécie de elevada exigência nutricional e, em decorrência, se implantado em solos com limitada disponibilidade de minerais, essa condição torna-se em fator limitante da produtividade, se não houver reposição desses minerais. Mesmo estabelecido em solos de média a elevada fertilidade natural, a reposição nutricional deve acontecer, o mais tardar, após o quinto ano de cultivo (Garcia et al., 1985). Dessa forma, a disponibilidade de nutrientes às plantas é fator primordial e o meio mais rápido de se elevar a produtividade do empreendimento agrícola.

Em novembro e dezembro de 2008 e de 2009, o produtor rural, a título de convencimento próprio, adubou 500 cacaueiros, utilizando $300 \mathrm{~g}_{\text {planta }}{ }^{-1}$ do composto NPK (20-5-20), em duas aplicações, em intervalo de 40 dias, em virtude da disponibilidade desta formulação no mercado rondoniense para a cultura do café. Também, em dezembro de 2009, por iniciativa própria e sem o devido respaldo de diagnose foliar, aplicou adubo foliar em toda a área, fazendo uso do fertilizante organomineral Mol Top ${ }^{\circledR}$ (carbono orgânico total: $10 \%$, nitrogênio: $11 \%$, potássio: $1 \%$ e ácido fosforoso: $6 \%$ ), tendo como matéria-prima: ureia, cloreto de potássio, ácido fosforoso, resíduo orgânico agroindustrial de origem vegetal e água. Por questão de comodidade e por desconhecer a importância do uso do fertilizante apropriado, o produtor não se dispôs a preparar a formulação de NPK recomendada para sua plantação de cacau. Mesmo assim, essas adubações se refletiram, positivamente, na produtividade do cacaual, no período de 2009 a 2011, cuja média se elevou para $387,3 \mathrm{~kg} \mathrm{ha}^{-1}$ de amêndoas secas de cacau, um aumento significativo em relação ao ano de $2008\left(180,4 \mathrm{~kg} \mathrm{ha}^{-1}\right)$, muito embora ainda 3 vezes abaixo das expectativas para a cultura, ou seja, de $1.200 \mathrm{~kg} \mathrm{ha}^{-1} \mathrm{ano}^{-1}$ (Tabela 1).

Apesar desse incremento produtivo, constatou-se a utilização de formulação desequilibrada para o cacaueiro, em razão da desproporcionalidade entre as quantidades de nutrientes aplicadas. Os resultados das análises químicas de solos (Tabela 1) revelaram que o ideal seria a utilização de 60-90-30 $\mathrm{kg} \mathrm{ha}^{-1}$ dos nutrientes $\mathrm{N}-\mathrm{P}_{2} \mathrm{O}_{5}-\mathrm{K}_{2} \mathrm{O}$, respectivamente (Chepote et al., 2012). Levando-se em conta a formulação e dosagem aplicada verifica-se que as aplicações de $\mathrm{N}$ - $\mathrm{P}_{2} \mathrm{O}_{5}-\mathrm{K}_{2} \mathrm{O}$ equivaleram, respectivamente, a $107 \%$, $18 \%$ e $213 \%$ da formulação apropriada (60-90-30 kg ha-1). Portanto, verificou-se o desequilíbrio entre as quantidades de nutrientes aplicadas.

Em setembro de 2011, diante da baixa resposta à aplicação de fertilizantes (Tabela 2), foram adotadas as seguintes providências: i) coletas de amostras de solo para novas análises químicas; ii) sondagem da profundidade do solo para averiguar existência de impedimento físico; iii) determinação do tamanho real do plantio e iv) levantamento dos estandes de cacaueiros e de plantas do sombreamento. Os resultados das novas análises químicas do solo corroboraram a necessidade de reposição nutricional (Tabela 2), utilizando a formulação $60-90-30 \mathrm{~kg} \mathrm{ha}^{-1}$ dos nutrientes $\mathrm{N}-\mathrm{P}_{2} \mathrm{O}_{5}-\mathrm{K}_{2} \mathrm{O}$, respectivamente, por se tratar de solos com baixo teor de fósforo e mediano de potássio. A acidez do solo, próxima da neutralidade, não justificou a prática de calagem. Na sondagem da profundidade do solo, por meio de 20 perfurações, evidenciou-se a inexistência de qualquer impedimento físico e/ou mecânico até $1,20 \mathrm{~m}$ de profundidade, situação favorável, portanto, ao pleno crescimento do sistema radicular das plantas instaladas, o que deve possibilitar o suprimento das necessidades em nutrientes e água, além da exploração das camadas inferiores do solo.

Confirmou-se que a área cultivada apresenta 2,24 ha, com população de 2.174 cacaueiros, o que caracteriza estande incompleto e a necessidade de replantio de 314 plantas, ou seja, de $12,6 \%$ de falhas no estande. $\mathrm{O}$ sombreamento definitivo compunha-se de 230 plantas, com predominância de bandarra $(84,8 \%)$, fato esperado por ser a espécie pioneira mais 

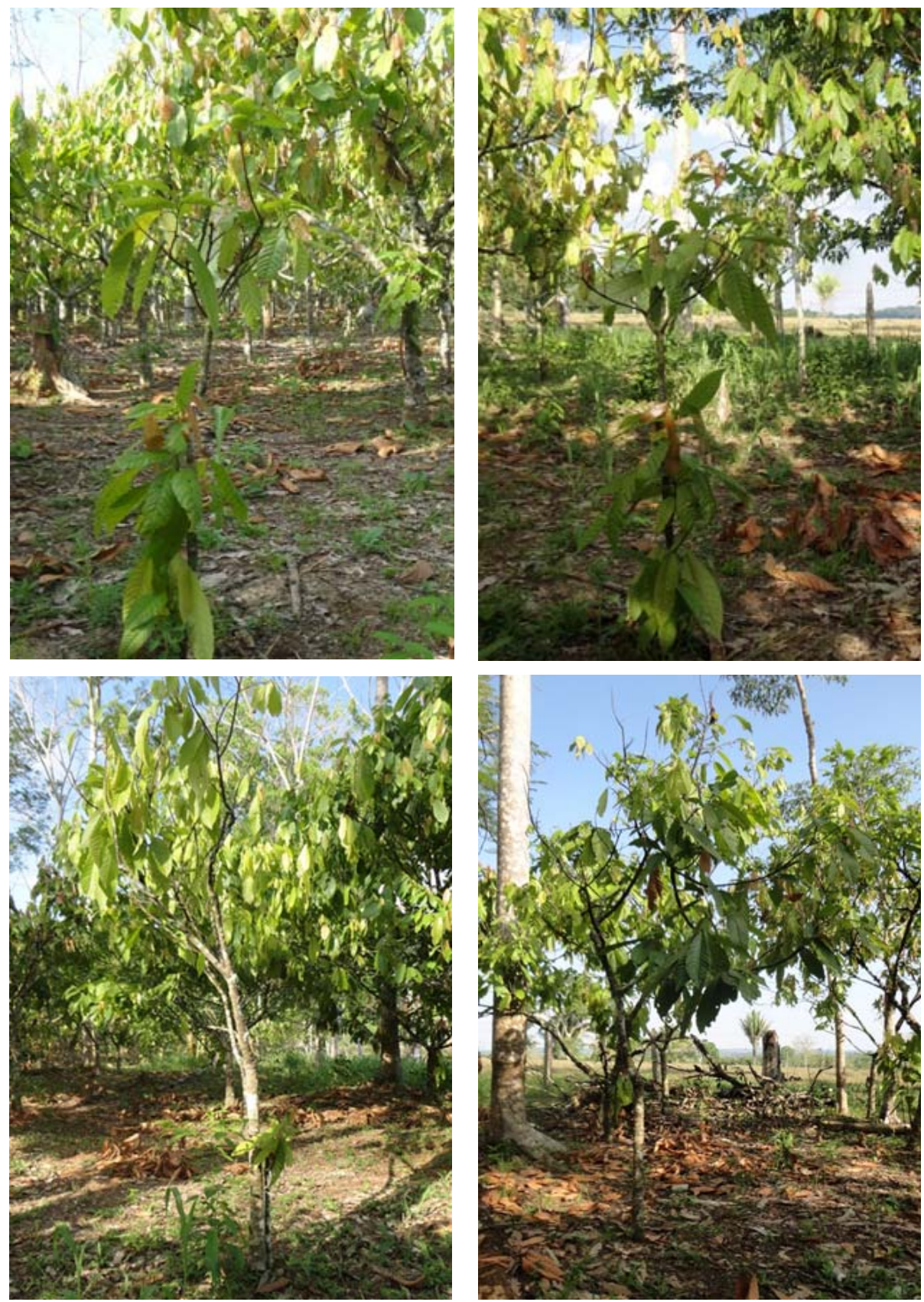

Figura 1 - Cacaueiros com sinais de raquitismo e sintomas de deficiência mineral no Sítio Rio Branco, Ouro Preto do Oeste, Rondônia.

Tabela 1 - Resultados das análises químicas do solo de 2,24 ha de intercultivo de cacaueiros e essências florestais no Sítio Rio Branco, Ouro Preto do Oeste, Rondônia

\begin{tabular}{c|c|c|ccccc|c|c}
\hline $\begin{array}{c}\text { Profundidade } \\
\text { da } \begin{array}{c}\text { amostra de solo } \\
(\mathbf{c m})\end{array}\end{array}$ & $\begin{array}{c}\mathbf{p H} \text { em } \\
\text { água }\end{array}$ & $\begin{array}{c}\mathbf{P} \\
\mathbf{m g} / \mathbf{d m}^{3}\end{array}$ & $\mathbf{K}$ & $\mathbf{C a}$ & $\mathbf{M g}$ & $\mathbf{H}+\mathbf{A l}$ & $\mathbf{A l}$ & $\mathbf{V}$ & $\mathbf{D a t a}$ \\
\hline $0-20$ & 6,10 & 2,0 & 1,72 & 53,4 & 3,3 & 31,4 & 0,0 & 65,0 & $07 / 2007$ \\
$20-40$ & 6,10 & 1,0 & 1,69 & 31,0 & 2,0 & 28,1 & 0,0 & 55,0 & $07 / 2007$ \\
\hline $0-20$ & 6,05 & 1,3 & 1,20 & & & 24,6 & 0,05 & 49,0 & $09 / 2011$ \\
\hline
\end{tabular}






bem adaptada àquelas condições ecológicas, conforme constatação de Almeida et al. (2009). Essa população de plantas sombreadoras significa uma densidade média de 102 componentes arbóreos ha ${ }^{-1}$, mais de três vezes a densidade recomendada para o sombreamento definitivo visando possibilitar de $50 \%$ a $60 \%$ de incidência solar, faixa de insolação considerada apropriada para cacaueiros adultos (Gramacho et al., 1992). Segundo Matos (2013), o espaçamento para o sombreamento definitivo varia em função do diâmetro da copa, sendo utilizados comumente os espaçamentos de $18,0 \mathrm{~m} \times 18,0 \mathrm{~m}, 21,0 \mathrm{~m} \times 21,0 \mathrm{~m}$ e $24,0 \mathrm{~m} \times 24,0 \mathrm{~m}$, o que corresponde, respectivamente, a 30,23 e 18 plantas por hectare. Na época, a elevada densidade arbórea não promoveu excesso de sombreamento aos cacaueiros em razão do pouco desenvolvimento das plantas, possivelmente em decorrência de deficiência mineral, aliada à imaturidade fisiológica das mesmas. Mesmo assim, para evitar futura competição no agrossistema, procedeu-se redução desse estande para 43 plantas $\mathrm{ha}^{-1}$, por meio de anelamento do tronco (remoção da casca) e aplicação de arboricida, sobretudo da bandarra, planta notável pela rapidez de crescimento e por atingir grande porte, porém com galhos frágeis que se quebram facilmente em ocasião de ventanias, fator depreciativo para um componente de sombreamento definitivo. Privilegiou-se a permanência na área de cultivo de componentes arbóreos com boa arquitetura de copa e melhor distribuição espacial.

Em novembro de 2011, no início do inverno amazônico, aplicou-se a primeira dosagem de nutrientes nas quantidades de $60 \mathrm{~kg}$ de $\mathrm{N}, 90 \mathrm{~kg}$ de $\mathrm{P}_{2} \mathrm{O}_{5}$ e $30 \mathrm{~kg}$ de $\mathrm{K}_{2} \mathrm{O}$ ha $^{-1}$ aplicadas em 1.071 cacaueiros. Para tanto, foram aplicados: $65 \mathrm{~kg}$ de ureia, $220 \mathrm{~kg}$ de superfosfato triplo e $25 \mathrm{~kg}$ de cloreto de potássio; sendo que o nitrogênio e o potássio foram aplicados em duas dosagens, no início (novembro) e final do período chuvoso (maio) e o fósforo aplicado de uma única vez, em novembro de 2011. Em ambas as aplicações, removeu-se o folhedo do solo para acelerar a incorporação dos nutrientes e reduzir perdas, retornando o mesmo logo após essa prática. Nos anos de 2012 a 2013, no início e final do período de chuvas, essas adubações foram repetidas, com os mesmos fertilizantes e quantidades anteriores, entretanto direcionadas para os outros 1.071 cacaueiros, que serviram de testemunha na primeira etapa da 
adubação. A partir do ano 2014, excetuando 2017, o produtor passou a adubar toda a lavoura, utilizando as quantidades recomendadas. Porém, em 2019, por iniciativa própria, aumentou a quantidade de adubo por planta para 430,0 g de NPK, sendo 200,0 g aplicados na primeira etapa da adubação (novembro) e o restante em fevereiro de 2020.

O patamar de produtividade dos anos de 2014 e 2015 , superior a $1.300 \mathrm{~kg} \mathrm{ha}^{-1}$, reflete tanto o elevado potencial genético da variedade hibrida explorada, como a eficácia da prática da fertilização química para atingir níveis superiores a $80 @$ ha $^{-1}$ ou a $1.200 \mathrm{~kg} \mathrm{ha}^{-1}$, conforme recomendação de Chepote et al. (2012). Observa-se também que esse patamar de produtividade foi obtido com o estande cacaueiro incompleto ( $12,6 \%$ de falhas), o que indica, indiretamente, a possibilidade de alcance de níveis de produtividade mais elevados, no tempo de maturidade fisiológico apropriado, se o produtor fizer o replantio do cacaual e se utilizar o manejo apropriado para tal. A não realização de adubação química em 2017, necessária para o bom desempenho produtivo do cacaual, se refletiu no decréscimo da produtividade em 2017 (Tabela 2), acrescido também da interferência do processo de clonagem para substituição dos cacaueiros híbridos.

O produtor rural destacou perdas de produção de cacau causadas pela broca-dos-frutos de $5 \%$, em 2014, e de $20 \%$, em 2015. A partir destes anos, não ocorreram perdas expressivas de frutos decorrentes do ataque da broca, muito provavelmente resultante do efeito do controle cultural adotado, conforme já descrito (Trevisan et al., 2012), aliado à redução do sombreamento definitivo. Registraram-se outras perdas na produção em anos anteriores em decorrência da incidência de vassoura-de-bruxa estimadas entre $1 \%$ e $2 \%$, e aquelas atribuídas à primatas (macacos), roedores (pacas) e aves (pica-pau), totalizando de $4 \%$ a $5 \%$ da produção.

\section{Clonagem do cacaual de variedades híbridas}

O elevado desempenho produtivo de cacauais de variedades clonais da Bahia e do Espírito Santo, com registros de produtividade superiores a $1.500 \mathrm{~kg} \mathrm{ha}^{-1}$ ano $^{-1}$ de amêndoas secas de cacau e até patamares mais elevados, quando sob irrigação (CEPLAC, 2002;
Lopes et al., 2004; Pires, Rosa e Macêdo, 2012; CEPLAC, 2014; Monteiro et al., s.d.; Pires et al., s.d.), estimulou o produtor a substituir sua lavoura de cacaueiros de variedades híbridas por variedades clonais. Para tanto, a partir da poda fitossanitária realizada de agosto a outubro de 2012 para o controle da vassoura-de-bruxa, suspendeu a prática de desbrota dos cacaueiros para preservar os ramos ortotrópicos emitidos na base do tronco, visando à substituição da copa.

Em novembro de 2012, o agricultor realizou a enxertia dos brotos basais de parte dos cacaueiros, através da garfagem de topo em fenda cheia, utilizando materiais (garfos) importados do estado do Espírito Santo dos clones: CCN 51, PH 16, SJ 02, PS 1319, CCN 10 e BN 34, com predominância dos dois primeiros. Adotaram-se os seguintes procedimentos básicos, conforme orientações técnicas da CEPLAC: i) uso de até três brotos basais por planta entre os mais próximos ao solo e com melhor disposição no tronco, eliminando-se os excedentes; ii) uso de garfos com 15 a $20 \mathrm{~cm}$ de comprimento contendo de três a quatro gemas; iii) uso de amarrilho ou barbante para facilitar a aderência do garfo ao porta-enxerto; iv) uso de saco plástico transparente para proteger o enxerto de intempéries e criar câmara úmida com condições microclimáticas favoráveis e v) realização da enxertia no campo nos horários de 7,0 horas às 10,0 horas, e de 16 horas às 17,30 horas, evitando-se, contudo, os dias chuvosos ou de instabilidade pluviométrica. Entre $20 \mathrm{e}$ 30 dias após a enxertia, quando os garfos apresentavam brotação com um par de folhas novas, com cerca de $5 \mathrm{~cm}$, removeu-se a câmara úmida e, 20 dias depois, o amarrilho.

Esse processo de enxertia dos cacaueiros híbridos por variedades clonais foi realizado, gradativamente, conforme a seguir: i) novembro e dezembro de 2012 350 plantas; ii) janeiro a junho de 2013 - 420 plantas; iii) janeiro a junho de 2014 - 720 plantas; iv) janeiro a junho de 2016 - 110 plantas; v) janeiro a junho de 2018 - 200 plantas, totalizando 1.800 cacaueiros enxertados, ou seja, uma densidade populacional de 804 plantas $\mathrm{ha}^{-1}$. O não replantio das falhas e o não pegamento de alguns enxertos, com morte de porta-enxertos, impediram a formação da densidade populacional esperada de 1.111 cacaueiros $\mathrm{ha}^{-1}$. Os materiais genéticos usados na enxertia em 2012 e 2013 foram 
oriundos de lavouras do estado do Espírito Santo, acondicionados em caixas de isopor e transportados por via aérea. A partir de 2014, o produtor utilizou garfos produzidos na própria área, nas plantas enxertadas em 2012.

A adoção da estratégia de enxertia do estande cacaueiro de forma paulatina, conforme descrito anteriormente, não impediu que houvesse o decréscimo de produção registrado em 2016 e 2017, coincidente também com a não aplicação de fertilizantes químicos em 2017. As elevadas produtividades de $1.481,5 \mathrm{~kg}$ $\mathrm{ha}^{-1}$ e de $2.057,1 \mathrm{~kg} \mathrm{ha}^{-1}$ de amêndoas secas de cacau, obtidas em 2018 e 2019, respectivamente, revelam a interação positiva do potencial produtivo das variedades clonais, com a adoção às tecnologias recomendadas, em especial a adubação química e o suprimento controlado de água. $\mathrm{O}$ agricultor passou a adotar a prática de irrigação a partir de julho de 2018, quando instalou sistema por micro aspersão, com espaçamento de $12 \mathrm{~m}$ x $12 \mathrm{~m}$ entre os aspersores, o que permitiu disponibilizar às plantas cerca de 28,0 litros de água por turno de rega, em intervalo de 7 dias, nos meses de julho e agosto, período de maior déficit hídrico na região. Em 2019, o suprimento de água foi estendido para os meses de julho a outubro, com turno de rega de três vezes por semana. Entretanto, este fornecimento de água aos cacaueiros está abaixo da necessidade da cultura, pois de acordo com as pesquisas de Leite (2013), ao avaliar cacaueiros com quatro anos de idade, em consórcio com bananeira e pau-brasil, sob gotejamento, o consumo hídrico médio foi de 31,5 litros de água planta ${ }^{-1} \mathrm{dia}^{-1}$. Também, Souza et al. (2016) citam que o consumo de água do cacaueiro adulto está em torno de 50 litros por dia.

A retirada constante de material genético para enxertia, visando o processo de substituição dos cacaueiros híbridos, nos anos de 2014 e 2015, seguramente contribuiu para a baixa frutificação das plantas enxertadas em 2012 e 2013. Assim, toda produção obtida na área em foco, até 2015, foi atribuída ao desempenho das variedades híbridas, enquanto a produção a partir de 2016 deveu-se, exclusivamente, às variedades clonais. Em outubro de 2018, visando complementar o estande da lavoura cacaueira, o produtor rural recebeu 330 mudas das variedades clonais CEPEC 2002, PH 19, CP 49, SJ 02, PS 1319, Ipiranga 1 e BN 34, produzidas na ESEOP.

\section{Análise socioeconômica da atividade cacaueira}

Para análise econômica da atividade cacaueira do Sítio Rio Branco foram computadas as despesas realizadas no período de 2005 a 2019, com mão-deobra para o manejo agronômico, aquisição de insumos agrícolas (fertilizantes, inseticidas, fungicidas, arboricida, ferramentas e combustível) e de equipamentos (roçadeira e pulverizador), além do transporte das amêndoas secas, despesas essas atualizadas, adotando-se uma taxa de juros de 2,5\% ao ano (a.a.), conforme já mencionado.

Para cálculo da mão de obra empregada, adotaramse os coeficientes técnicos constantes em BRASIL, 2015, ajustados após entrevista com o proprietário, em face das peculiaridades do empreendimento. Por exemplo, o cacaual em foco, por se localizar isolado de outras plantações de cacau daquela região, apresenta baixíssimo nível de infecção pelo patógeno M. perniciosa. Em decorrência, os gastos com mão de obra para a poda fitossanitária foram reduzidos praticamente pela metade ao preconizado no sistema de produção (BRASIL, 2015).

A Tabela 2, reúne os valores obtidos na análise econômica, os quais retratam o desempenho do manejo agronômico no período em análise, que refletiu uma TIR de 26\%. Segundo Silva, Jacovine e Valverde (2005) valores de TIR entre $20 \%$ e $40 \%$ demonstram a viabilidade econômica do sistema de produção. Considerando todo o período para o cálculo da TIR, em torno de $65 \%$ acumulado, e os VPL de cada ano, pressupõe-se que o produtor rural destinou sua renda líquida em investimentos tanto na atividade cacaueira, como em outras atividades econômicas, pois sua propriedade é diversificada.

Os patamares de produtividade obtidos pelo produtor rural superiores aos esperados no sistema de produção para a região (Reis e Silva Neto, 2013), em especial nos intervalos dos anos de 2014/2015 e $2018 / 2019$, retratam que a adoção correta das práticas de manejo resultou em maior performance produtiva tanto para as variedades híbridas como para as variedades clonais.

Nos anos em que o VPL foi negativo, o que indica que o investimento não foi rentável, a propriedade se manteve em função dos resultados dos anos anteriores 
e seguintes. Isso fica mais claro quando se observa a relação entre RBD, DBD e VPL melhor retratado na Figura 2, que expressa o desempenho do SAF quanto ao uso da tecnologia preconizada. Observa-se que o RBD teve seu melhor desempenho no ano de 2019, da mesma forma que o VPL, com valores líquidos de: $\mathrm{R} \$ 47.594,83$ e $\mathrm{R} \$ 15.732,91$, respectivamente, compensando a DBD de: $\mathrm{R} \$ 24.239,23$, performance resultante da maturidade produtiva da maioria das plantas clonais em cultivo e do uso correto da tecnologia.

Nos anos anteriores ocorreram oscilações, com discrepâncias da renda em alguns anos, o que indiretamente indica que o manejo agronômico da atividade cacaueira não foi mantido de forma regular. Dessa forma, presume-se que o produtor rural estava se adequando ao uso de novas práticas de manejo em virtude da utilização de novos materiais genéticos, que têm demonstrado boa adaptação às condições ecológicas regionais.

As diversas oscilações e discrepâncias dos valores de VPL ocorridos no período em análise poderiam impactar o desempenho da atividade cacaueira, caso o mercado de cacau estivesse em baixa nas Bolsas de Mercadoria e Futuro (BM\&F), pois trata-se de uma commodity agrícola que sofre os reflexos da Lei de Oferta e Procura, ocasionados pelos estoques de mercadoria, pelos agentes econômicos e/ou pelos efeitos sazonais.
Com esses resultados, registra-se a melhoria e/ou avanço do desempenho da atividade cacaueira, em especial no ano de 2019, avanço esse que pode promover maior bem-estar social por meio da empregabilidade da mão de obra familiar, maior geração de rendas e melhorias nos serviços ambientais.

\section{Conclusão}

- A adoção correta das práticas de manejo agronômico resulta em maior produtividade tanto para as variedades híbridas como para as variedades clonais.

- A análise econômica do período avaliado revela Taxa Interna de Retorno (TIR) de $26 \%$, o que demonstra a viabilidade econômica do sistema de produção.

- A Renda Bruta Descontada - RDB e o Valor Presente Líquido - VPL tiveram melhor desempenho no ano de 2019, com valores líquidos de: $\mathrm{R} \$ 47.594,83$ e R\$15.732,91, respectivamente, coincidente com a maior produtividade obtida.

\section{Agradecimentos}

Ao produtor rural Armando de Jesus, pelas informações prestadas e por disponibilizar a área para realização desta pesquisa.

\section{Desempenho Econômico da Atividade Cacaueira}

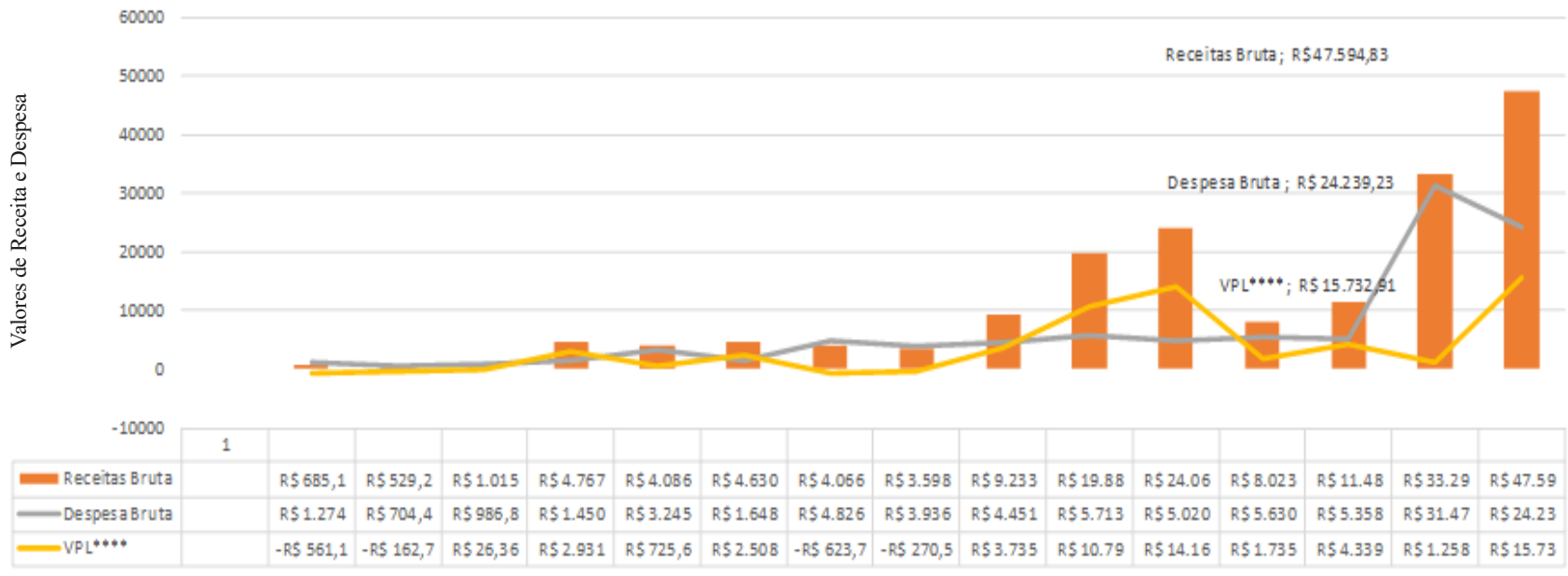

Figura 2 - Desempenho econômico da atividade cacaueira no Sítio Rio Branco, município de Ouro Preto do Oeste, Rondônia. 


\section{Literatura Citada}

ALMEIDA, C. M. V. C. de et al. 2009. Diversidade de espécies arbóreas e potencial madeireiro em sistemas agrossilviculturais com cacaueiro em Ouro Preto do Oeste, Rondônia, Brasil. Agrotrópica (Brasil) 21(1):73-82.

ALMEIDA, C. M. V. C. de; MATOS, P. G. G. de; DESTRO, W. 2011. Contribuições da CEPLAC para o processo de colonização de Rondônia: 40 anos de história e prospectiva. Porto Velho, RO, CEPLAC. 122p.

BRASIL. MINISTÉRIO DA AGRICULTURA, PECUÁRIA E ABASTECIMENTO. 2015. Implantação do cacaueiro em sistemas agroflorestais. MAPA/CEPLAC. Brasília, DF, Mapa/ACS. 76p.

COMISSÃO EXECUTIVA DO PLANO DA LAVOURA CACAUEIRA - CEPLAC. 2002. Novas variedades clonais resistentes à vassourade-bruxa: recomendação varietal. Itabuna, CEPLAC/CEPEC/SEMEQ.

COMISSÃO EXECUTIVA DO PLANO DA LAVOURA CACAUEIRA - CEPLAC. 2014. Indicação de variedades clonais de cacaueiros. Ilhéus, CEPLAC/CEPEC. Comunicado CEPLAC/ CEPEC No2/2014.

CHEPOTE, R. E. et al. 2012. Aptidão agrícola e fertilidade de solos para a cultura do cacaueiro. In: Valle, R. R. M. Ciência, Tecnologia e Manejo do Cacaueiro. pp.67-113.

GARCIA, J. de J. da S. et al. 1985. Sistema de produção do cacaueiro na Amazônia brasileira. Belém, PA, CEPLAC/DEPEA. 118p.

GOMES, I. 2005. Sustentabilidade social e ambiental na agricultura familiar. Revista de Biologia e Ciências da Terra (Brasil) 5(1).

GRAMACHO, I. C. P. et al. 1992. Cultivo e beneficiamento de cacau na Bahia. Ilhéus, BA, CEPLAC.

FUNDAÇÃO INSTITUTO BRASILEIRO DE GEOGRAFIA E ESTATÍSTICA - IBGE. 2020. Levantamento sistemático da produção agrícola. Pesquisa mensal de previsão e acompanhamento das safras agrícolas no ano civil. Março de 2020.
LEITE, M. S. B. 2013. Consumo hídrico do cacaueiro jovem irrigado por gotejamento em consórcio com bananeira e pau-brasil. Dissertação Mestrado. Ilhéus, BA, UESC. 68p.

LOPES, M. A.; CONTINI, E. 2012. Agricultura, sustentabilidade e tecnologia. Especial Embrapa. Agroanalysis. pp.27-34.

LOPES, U. V. et al. 2004. On farm selection for witches' broom resistance in Bahia, Brazil - a historical retrospective. Agrotrópica (Brasil) 16(3):61-66.

LOPES, U. V. et al. 2018. Recomendação clonal de cacaueiros 2018 - Cepec 2176 e Cepec 2204. Itabuna, BA, MAPA/CEPLAC.

MATOS, P. G. G. de. 2013. Plantio dos sombreamentos provisórios e definitivo. In: Silva Neto, P. J. da. et al. Manual técnico do cacaueiro para Amazônia brasileira. Belém, PA, CEPLAC/SUEPA. pp.39-41.

MONTEIRO, W. R. et al. s.d. Recomendação de variedades clonais com base em dados dos ensaios multilocais. Itabuna, BA, CEPLAC/ CEPEC.

PIRES, J. L.; ROSA, E. S.; MACÊDO, M. M. 2012. Avaliação de clones de cacaueiro na Bahia, Brasil. Agrotrópica (Brasil) 24(2):79-84

PIRES, J. L. et al. s. d. Indicação de variedades de cacau para cultivo comercial - Rede de avaliação de clones em larga escala. Itabuna, BA, CEPLAC/CEPEC.

REIS, S. M. dos; SILVA NETO, P. J. 2013. Índices de produtividade. In: Silva Neto, P. J. da. et al. Manual técnico do cacaueiro para Amazônia brasileira. Belém, PA, CEPLAC/SUEPA. pp.199200.

SANTOS, H. G. dos et al. (eds.). 2006. Sistema brasileiro de classificação de solos. 2ed. Rio de Janeiro, RJ, Embrapa Solos. 306p.

SILVA, M. L. da; JACOVINE, L. A. G.; VALVERDE, S. R. 2005. Economia Florestal. 2 ed. Viçosa, MG, UFV. 178p.

SOUZA, C. A. S.; AGUILAR, M. A.; DIAS, L. A. dos S.; SIQUEIRA, P. R. 2016. Relações hídricas e irrigação. Cacau do plantio à colheita. pp.178199. 
SUSTENTABILIDADE, 2020. Sustentabilidade na Agricultura: como a agricultura sustentável pode ajudar o mundo. Tecnologia no Campo. Disponível em:https://tecnologianocampo.com.br/ sustentabilidade-na-agricultura/ Acesso em: 15 out. 2020.
TREVISAN, O. et al. 2012. Manejo integrado das pragas do cacaueiro da região Amazônica. In: Valle, R. R. M. Ciência, Tecnologia e Manejo do Cacaueiro. pp.161-185. 